\title{
Escritura y movimiento dancístico como vía de inscripción subjetiva en la adolescencia
}

The writing and the dance movement as a way of subjective inscription in adolescence

\author{
Andrea Molina Ovares ${ }^{1}$ \\ Damián Herrera González²
}

Fecha de recepción: 20-2.20

Fecha de aprobación: 13-10-20

\begin{abstract}
Resumen
Este artículo consiste en una lectura psicoanalítica del proceso creativo y de las obras artísticas realizadas por un grupo de adolescentes del cantón de San Ramón en espacios de expresión de danza y literatura. Concluye que la creación artística posibilita a las personas adolescentes pensarse y elaborar un discurso propio, contribuyendo a la construcción subjetiva de forma individual y colectiva. Además, los discursos sobre la muerte, el suicidio y la tragedia hacen un llamado a dejar de tratar estos temas como un tabú.
\end{abstract}

Palabras clave: Adolescencia, danza, escritura, psicoanálisis, creación.

\begin{abstract}
This article carries out a psychoanalytic analysis of the creative progress and artistic works made by a group of adolescents from the región of San Ramón in dance and writing spaces. It concludes that the artistic creation enables adolescents to think and elaborate their own discourse, contributing to the subjective construction of individual and collective forms. In addition, the speeches on death, suicide and tragedy call for a stop to treat these issues as a taboo.
\end{abstract}

Keywords: Adolescence, dance, writing, psychoanalysis, artistic creation.

\footnotetext{
1 Licenciada en Psicología. Escuela de Psicología/Centro de Investigaciones sobre Diversidad Cultural y Estudios Regionales, Universidad de Costa Rica, Costa Rica. Correo: andrea.molinaovares@ucr.ac.cr

2 Escuela de Psicología/Centro de Investigaciones sobre Diversidad Cultural y Estudios Regionales, Universidad de Costa Rica, Costa Rica. Correo: damian.herrera@ucr.ac.cr
} 


\section{Introducción}

Este artículo presenta un análisis de las producciones artísticas realizadas en el marco del proyecto: "Inscripción de la subjetividad a través de la escritura y el movimiento dancístico: identidades, temores y experiencias ligadas al existir adolescente", perteneciente al Centro de Investigaciones sobre Diversidad Cultural y Estudios Regionales (CIDICER) de la Universidad de Costa Rica. Este consistió en facilitar procesos de creación a partir de la literatura y la danza, con el fin de analizar los elementos relacionados a la construcción de sí y a la experiencia de ser adolescente presentes en las obras desarrolladas.

El proyecto inició en el año 2017, con la apertura de dos talleres dirigidos a personas adolescentes del cantón central de San Ramón, y finalizó en el 2018 con una muestra coreográfica y literaria llamada Corpografías. El espacio realizó un acercamiento a estas prácticas artísticas a través de la enseñanza de técnicas y ejercicios y, a su vez, posibilitó la expresión propia y la discusión de temáticas de interés propuestas por las personas jóvenes o evidenciadas en sus procesos de creación.

La metodología buscó nutrirse del arte ${ }^{3}$ y de las posibilidades que brinda para la reflexión y la investigación académica. La expresión, a través de medios artísticos, representa una forma de escritura que retrata algo de la realidad, conlleva una producción propia que dice algo sobre sí misma y sobre el entorno en que se vive. El movimiento y la escritura contienen en su esencia una intención; intención que desprende elementos subjetivos que dejan su huella en el espacio y en el papel.

El artículo efectúa una lectura psicoanalítica de esas huellas, analizando el proceso y la producción artística realizada; pretende ser un aporte al entendimiento del individuo y de su entorno, así como del papel de los procesos creativos en la significación del mundo adolescente. No se buscó psicoanalizar la obra o a sus autoras y autores, en el sentido de aplicarles la teoría, por el contrario, una lectura psicoanalítica valora los elementos fundamentales propuestos en las obras para abrir un diálogo respetuoso con estos.

A continuación, se expone la base teórica que circunscribe la investigación, la cual se fue nutriendo durante el proceso, conforme el lazo entre la práctica artística y el análisis de los discursos y las creaciones empezó a sugerir ciertas líneas de discusión. Posteriormente, se presenta la propuesta metodológica para la lectura psicoanalítica, una breve descripción de los talleres y finalmente, el análisis y discusión del proceso.

\section{El trazo escrito y bailado}

Las artes entendidas como una forma de retratar o transmitir un sentido o un sentimiento, de provocar admiración, de acercarnos a lo bello, a lo sublime; son también un medio que plasma la subjetividad ${ }^{4}$ de quien se dispone al ejercicio artístico. Esta investigación considera la danza y la literatura como parte de estas artes que dicen o intentan decir, a través del cuerpo y la letra; que contiene en su esencia una intención consciente e inconsciente de quien la produce, así como lo manifestaba Freud (1986b): "No le resulta difícil al psicoanálisis pesquisar, junto a la parte manifiesta del goce artístico, una parte latente, pero mucho más eficaz, que proviene de las fuentes escondidas de la liberación de lo pulsional” (p. 189-19o).

Entonces, la expresión artística tiene un valor comunicativo, pero también habla de la tendencia del sujeto al diálogo consigo mismo, construye nuevos puntos de encuentro con la realidad circundante y la resignificación propia. El sujeto tiene la posibilidad de plasmar trazos de su identidad en el papel y el movimiento; el acto creador toca y marca, como plantea Bordeu (1995) acerca de la escritura: “... es uno de los lugares en los que el inconsciente encuentra un espacio para manifestarse” (p. 1).

3 Esta investigación mira el arte como una forma humana de expresión y no tiene como objetivo analizarlo desde una conceptualización apreciativa y clasificatoria establecida por cierto canon o crítica artística.

$4 \quad$ Al hablar de subjetividad no nos referimos a aquello que es contrario a la objetividad, sino a la concepción psicoanalítica de los procesos inconscientes que se ven implicados en la construcción del sujeto y su psique. Maruottolo (2013) plantea la subjetividad como ese espacio donde se mezcla lo interno y lo externo del sujeto; lo individual (instintivo) y social (cultural). 
Desde esta perspectiva psicoanalítica, se piensa el acto creativo como un lugar donde afloran los procesos de subjetivación en el que se juegan elementos como la sublimación, el narcisismo, el goce, la pulsión de vida y muerte, entre otros elementos inherentes a toda creación e imposibles de evitar en el rastro del sujeto; por tanto, es posible pensar que se escribe y se baila más allá de lo que se sabe, más allá de lo manifiesto.

\subsection{La marca en lo escrito}

Es necesario explorar la relación del autor con su obra para aclarar las posibilidades de expresión, comunicación y/o construcción de sí, que se entrelazan en esta unión. Sostenemos que el acto de escribir implica una inscripción subjetiva, porque se vincula con ejercicio de extraer algo de sí y cederle paso en el papel; posibilita producir algo con una parte de sí, lo que de cierta forma es de-construirse y re-construirse.

En primer lugar, surge la pregunta por el carácter real de lo que se escribe, suponiendo que es la ficción quien reina en el texto: ¿qué valor real dar a lo que nace de un ejercicio que implica lo imaginario? Hubier (citado en Poe, 2007a) plantea que "...la escritura en primera persona construye una especie de espacio transicional entre la realidad y la ficción, donde todo lo que ocurre es siempre y paradójicamente imaginario y verdadero" (p. 103). Esto se anuda con lo dicho por Freud (1986a) en $E l$ creador literario y el fantaseo: “...el poeta hace lo mismo que el niño que juega: crea un mundo de fantasía al que toma muy en serio, vale decir, lo dota de grandes montos de afecto" (p. 128). Por su parte, Murillo (2010) señala que el realismo del texto es secundario, el autor no se encuentra forzosamente en el centro de su escritura y podría ser solo una silueta: “...lo importante es que venga a ubicarse en una esquina de su obra, que refleja entonces su presencia como lo haría un espejo" (p. 119).

De este modo, se habla de una ficción "muy real" que convoca a la extrañez de sí, hay algo que se está escribiendo sobre sí mismo que ni quien escribe lo sabe, es una forma de plasmar fragmentos de la propia vida. En este sentido, Poe (2007a) manifiesta que “... la ficción no se opone a la verdad sino que la constituye” (p. 107) y podría agregarse que incluso la transforma por lo que, para objeto de esta investigación, no se considera una polaridad entre lo real y lo ficticio, sino como ingredientes de un espacio que puede ser el sujeto o su obra.

A través de la ficción, quien escribe llega a la configuración de una relación consigo mismo, donde logra posicionarse desde otro lugar y verse o leerse. Esto puede ser, simultáneamente, una relación extraña y violenta, ya que no es poca cosa esto de "relacionarse consigo mismo", simulando un verse adentro desde afuera; al mismo tiempo que se desarrolla el arte de construir un escrito que permite extender el imaginario individual y social. Aquí es donde la escritura ejerce su función amortiguadora, ya que quien se observa de esta forma no mira la imagen de un espejo, aunque vea claramente algo de sí, no es una devolución intacta de su imagen. Poe (2007a) lo define como “... la posibilidad de devenir otro(s), de convertirse en un personaje de ficción que podría atenuar el sentimiento de fracaso ante lo irrealizado, ante lo que no pudo ser (¿dicho?) en la vida del escritor” (p. 89).

Asimismo, Poe (2013) sostiene que “... la pulsión creadora, vital, erótica es la fuente de una imaginación desbordante que transforma- incluso los aspectos autobiográficos más desgarradores- en autoficciones” (p. 26). Sería esta la posibilidad que da la ficción de una reivindicación, donde el autor se construye sin límite establecido sobre lo que puede ser o quién puede ser ahí en su relato. Para Murillo (2010), se trata de un proceso donde el escritor se irrealiza, fabula a partir de lo que ha vivido, se desrealiza y “... se inventa una nueva existencia” (p. 85). De esta forma, plantea una relación de la ficción que es inversa: “... o bien se introyecta la fábula a sí o bien se proyecta el sí mismo (yo) en la fábula” (Murillo, 2010, p. 85). Este crearse y devenir otro tiene íntima relación con los escritos en los que hay invención de personajes, donde el escritor los crea y los habita, así como lo describe Grossman (2011):

Se convierte en el espacio donde sus personajes pueden hacer realidad sus caracteres, deseos y hazañas, y dar rienda suelta a los impulsos, tonterías, locuras y conductas afectivas, de lo que el escritor es incapaz porque es un hombre 
específico (es decir, con un "final”, con límites y restricciones) y porque estas propensiones, deseos y hazañas le amenazan o, en cierta medida, le contradicen y, a veces, incluso le desmienten. (p. 34)

De este modo, Grossman (2011) evidencia que en esa invención no todo se puede "falsificar", el escritor se traiciona en algún momento y revela un trazo propio, algo que lo trastoca y deja ver su propia particularidad. Ligado a esto, Ioskyn (2013) dice que en la búsqueda de esa particularidad se debe mirar el uso específico de las palabras y la manera en que se cuenta una historia, no la historia misma; es en el adjetivo de lo específico donde se halla el trazo único, ese que se repite, que es una tenacidad pulsional. Se evidencia que algo propio se entrelaza en el proceso creativo, pero se debe tener claro que una lectura psicoanalítica no busca "desenmascarar" al autor, su historia o su inconsciente, pues sería absurdo intentar psicoanalizar la obra. Lo que realmente interesa es dialogar con los elementos fundamentales e insistentes que dejan huella, tomando en cuenta que estos se nutren de su subjetividad.

\subsection{Efecto estético e inscripción a través del cuerpo}

Partiendo de la premisa de que el cuerpo puede ser metáfora y de que el movimiento también es un texto a leer, consideramos la existencia de infinidad de escrituras y de lienzos para plasmarlos: la escritura en la piel, el acto, la repetición, el síntoma y el gesto. La bailarina Isadora Duncan, considerada la creadora de la danza moderna, dijo alguna vez: "yo podría bailar ese sillón”, planteando la posibilidad de la danza para interpretar, para decir, para nombrar. Tal como afirma Volosín (2002), las palabras pueden apuntar al contenido, pero también pueden ser acciones. El cuerpo es lenguaje, las palabras tocan el cuerpo, el afecto, la emoción, por ello, hay cosas que se pueden decir sin recurrir a las palabras o inclusive, únicamente se pueden llegar a decir sin involucrarlas. Ciertas experiencias de vida encuentran límites en el lenguaje a la hora de describirlas, de definirlas, pero es posible mediante "... la creación de metáforas a través del lenguaje artístico" (Hounie, 2014, p. 174-175).
Igual que en la escritura, en el movimiento corporal hay un saber del que no se es consciente. Barthes (1974) señala que el placer del texto es ese momento en que el cuerpo sigue sus propias ideas, pues no tiene las mismas ideas que el sujeto que escribe. Esto remite a que una de las formas en las que el inconsciente se evidencia es a partir de la libre asociación, en el sentido psicoanalítico y, precisamente, la improvisación en la danza responde al anhelo de expandir las posibilidades de asociación libre y de movimiento fluido. Cuando se trabaja mediante la danza y sobre todo, con la improvisación del movimiento, no se trata de bailar una escena o una frase construida, sino de bailar a partir del desequilibrio, del apoyo y el vacío, como lo menciona Mariscotti (2013): “... se libra a un dictado que escribe desde un saber hacer allí con... aquello inasible, las huellas del cuerpo propio" (p. 3). La danza es una suerte de vaciamiento, también se baila desde el recorrido pulsional del sujeto.

Mariscotti (2013) señala que la danza contemporánea se relaciona estrechamente con las maneras de leer y escribir, lo que en el psicoanálisis se hace de la deriva de la pulsión en lo dicho; se trata del cuerpo como espacio simbólico. Los movimientos corporales pueden ser antecedentes o complementos de la palabra, siendo justamente aquí donde encuentra sentido el proceso de metaforización que se logra mediante la danza y que es importante elaborar, posteriormente, a través de la palabra, ya que se abre una puerta de conocimiento para el mundo psíquico no verbal.

La danza, en su condición de arte, también tiene la posibilidad de hacer del dolor otra cosa, no como una especie de terapia o de anestesia, sino en su efecto estético:

Una línea de significaciones interesantes para considerar el tema, es la que se desprende de la relación entre dos palabras griegas con aires

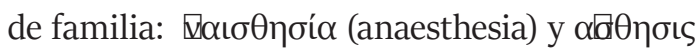
(aisthesis). Ambas contienen la misma raíz, pero se separan para dar origen una a la anestesia y la otra la estética. Así entonces «la an-estesia resulta ser la negación de la aisthesis griega, le estética, la del goce sensible, hermana del sopor, del letargo, eclipse de la sensibilidad». (Steiner, 1998, citado en Hounie, 2014, p. 174) 
Por lo tanto, la estética como experiencia vinculada al hecho artístico permite "... componer lo indecible no para decirlo, sino para decir de lo imposible de decir" (Hounie, 2014, p. 174).

La danza tiene la posibilidad de diseñar una estética a partir de anudamientos y enlaces, ofreciéndose a bordear lo que no es palabra y aconteciendo así, la creación como posibilidad. Precisamente por esto, se considera que la danza tiene la capacidad de hacer del movimiento un texto ${ }^{5}$ que nos habla del sujeto y de su entorno; lo estético viene a ser esa posibilidad de construir desde lo subjetivo.

\subsection{Lo "oscuro" como una posible fuente de creación}

Históricamente, se ha establecido una relación entre el arte y lo comúnmente asociado a la oscuridad (la noche, lo triste, las sombras), como si se necesitara de una "zona tenue" para que el sujeto vuelva la mirada hacia lo interno y pueda decir algo de sí6.

Como lo menciona Molina (2000), haciendo referencia a las acotaciones de Freud sobre la escritura, la miseria relativa y la soledad se convierten en elementos indispensables para el trabajo escritural intenso. Al respecto, Poe (2007a) se pregunta por qué un duelo es el motivo para escribir sobre sí mismo y esa posición subjetiva del doliente lo lleva a escribirse/inventarse. Da la sensación de que para crear, tiene que quebrarse algo primero, para dar un impulso o un motivo de la creación.

Por otro lado, el acto de creación también podría permitir elaborar, resignificar y transformar; el sujeto no solamente crea ante una pérdida, sino que al crear pierde: “... el sujeto debe sacrificar algo para escribir(se). Pero en esta pérdida deviene otro, se modifica" (Poe, 2007b, p. 14).
Se debe aclarar que no porque se escriba o se dance sobre un duelo, sobre una falta, se hallará lo perdido; pero hay una forma de inscribir este dolor que provoca la carencia del ser, dolor que a su vez se vuelve impulso aún cuando se da cabida a la soledad, asumiéndola. No se pretende llegar a ese sueño de completud de lo que se perdió, sino que se “... intenta sólo decir algo que tal vez no se ha dicho así” (Morales, 2000, p. 11).

Según Molina (2000), “... no es extraño que el poeta escriba cuando la pérdida lo ha hecho suyo, cuando las palabras son la única posibilidad de reunir los pedazos" (p. 121). Es un camino que permite acercarse a lo perdido, como una forma de apalabrar lo que se perdió, pues como afirma Freud (1986c) en su escrito sobre el duelo y la melancolía, el sujeto “... sabe a quién perdió, pero no lo que perdió en él” (p. 243).

Este recorrido es determinante para entender que en la manifestación artística es imposible no dejar un rastro que revela algo de sí: incluso en la puntuación, en los movimientos deliberados, en los silencios, en lo nimio; todo se conjuga en una suerte de construcción donde se instauran las huellas de lo propio. De esta forma, no se trata de producir una verdad, sino de tomar un lugar en ella, de construir nuevas narrativas, de encontrar al sujeto “... constituido por sus propias letras” (Ioskyn, 2013, p. 7).

\section{Un espacio para la palabra y el movimiento}

Muchas veces se trabaja con jóvenes desde las artes como medio de distracción o descarga, reduciéndose a una conexión terapéutica. A pesar de que en estos ejercicios se realiza un encuentro con actividades potencialmente liberadoras y productoras, no se le da todo el valor a dicho espacio, tendiendo a percibirse como algo anestésico y no estético, en función, solamente, de la catarsis y no de la construcción.

5 Ramiro Guerra (2013) fundador de la danza moderna en Cuba, alumno de grandes coreógrafos como Martha Graham, Doris Humprey y Charles Wiedman, es categórico en afirmar que si bien la danza se devela como la manifestación por excelencia del movimiento, a su vez es un constante generador de un sistema de signos, que conforman un lenguaje que apela a la espiritualidad y que el conjunto de gestos presentes en la danza, como un sistema condensado significativo contiene una polisemia que exige investigación, pues la intención adherida al mismo puede dar una determinada producción de sentido o su contrario.

6 Sin embargo, se debe aclarar que no se considera esta como condición inherente a la producción artística. Es mencionada en este escrito por la relevancia que adquirió en las distintas temáticas presentes en las creaciones de las personas adolescentes participantes. 
La propuesta de este trabajo se diferencia de otras intervenciones similares llevadas a cabo en el país, porque le da un lugar al arte como material de lectura. Alejándonos así de las propuestas que utilizan el arte como una forma de intervención terapéutica en una población con una característica específica, donde se estudian sus efectos y no tanto el contenido o lo que se dice por medio del arte (Sebiani, 2005; Quesada y Quesada, 2004; Salas y Arce, 2005; Brenes y Lobo, 2009).

Este proyecto no buscó trabajar con una población específica, en el sentido de que esta contara con una "problemática" establecida, sino con jóvenes (hombres y mujeres entre los 13 y 17 años) que desearan acercarse a estas dos prácticas artísticas, sosteniendo que un grupo de jóvenes en ese espacio, tendría la oportunidad de cifrar su realidad, sus preocupaciones, sus intereses y representar el mundo que les rodea a partir de sus creaciones. A modo de paréntesis, se debe subrayar una particularidad del pueblo de San Ramón, el cual es reconocido como "tierra de poetas" (Barrantes, 2010), donde el arte ha sido un fuerte elemento de identificación de sus pobladores, por lo que esta podría trastocar algunas raíces identitarias de las personas jóvenes.

Cada taller consistió en 18 sesiones, en el caso del taller de literatura, fue en un espacio de aprendizaje y discusión de las bases teóricas y críticas de la literatura, con ejercicios prácticos de escritura, expresión y análisis. Algunos de los temas abordados fueron: técnicas y géneros literarios, metáforas y otras formas literarias, estilo propio, elección del tema, relación entre el escritor y su texto, entre otros. Vale aclarar que, a nivel práctico, el taller promovía la improvisación y libertad de creación.

Por su parte, el taller de danza trabajó temas como la historia y técnicas básicas de la danza moderna, la percepción corporal, la expresión a través del movimiento, la danza somática, relación psique-cuerpo, movimiento creativo, improvisación, ejercicios de escritura con el cuerpo.
Adicionalmente, ambos talleres abrieron espacios para la discusión de temas de interés propuestos por el grupo. Al finalizar, se llevó a cabo la muestra coreográfica y literaria Corpografías, presentada de forma pública a la comunidad. Además, se editó un libro que recopila los principales textos producidos en los talleres y un video7 que muestra distintos momentos del taller de danza y la muestra coreográfica. Es sobre los materiales presentados en dicha muestra artística (3 coreografías colectivas), sobre los contenidos del libro (9 textos individuales) y el video, sumado a la convivencia, diálogo, textos y montajes, que se lleva a cabo el análisis de este artículo8.

\section{Boceto para una lectura psicoanalítica}

El tramo final del proyecto busca dialogar con los elementos principales de las producciones artísticas, en tanto estos puedan hacer sugerencias sobre el existir adolescente y el mundo que se habita. La investigación se plantea desde un enfoque de corte cualitativo de alcance descriptivo y exploratorio; según Gurdián (2007), dicho enfoque requiere una “... postura metodológica de carácter dialógico en la que las creencias, los valores, los mitos, los prejuicios y los sentimientos, entre otros, son aceptados como elementos de análisis para producir conocimiento sobre la realidad humana” (p. 95). Además, se resalta lo expuesto por Hernández, Fernández y Baptista (2014), quienes consideran que una característica fundamental de la investigación cualitativa es su flexibilidad en todas las etapas de la investigación; los ejes de análisis y preguntas pueden irse contestando o surgiendo en cualquier momento.

Para el análisis, más que un método (en cuanto a pasos establecidos e inamovibles), se utiliza una serie de sugerencias que se adoptan de varias propuestas de lectura en medios artísticos desde el psicoanálisis. Dicha metodología se relaciona con la técnica del boceto en las prácticas artísticas, el cual no es considerado solo un

7 Los textos y el video se pueden observar en: https://cidicer.so.ucr.ac.cr/recursos/video/corpografias

8 Consolidamos la utilización del video como material de investigación y, a su vez, como estrategia que posibilita el análisis y no únicamente como una forma de recolección de información, así como lo menciona García (2011): “... pensar el uso del video como herramienta de investigación ... que busque acercarse a la realidad a través de las imágenes y de los recursos técnicos, estéticos y expresivos que ofrecen los medios audiovisuales ... requiere considerar la imagen no solo como instrumento para almacenar, comprobar y verificar datos, sino como objeto" (p. 3); siendo este un objeto que permite la reconstrucción de una realidad y de las distintas lecturas de la misma. 
trabajo preliminar, sino que tienen una finalidad como obra terminada donde no sobra o falta algo; demanda una cuidadosa práctica de selección y composición, exigiendo un proceso sistemático de enfoque y análisis (Canal, 2013).

Este acercamiento metodológico se aproxima a lo que Denzin y Lincoln (2005) denominan un bricolage, es decir, un montaje en el que diferentes imágenes son yuxtapuestas o superpuestas una sobre otra para crear un cuadro. El investigador puede ser visto como alguien que borda retazos (quilts) o que ensambla las imágenes que constituirán el filme, utilizando la estética y las herramientas materiales de su oficio, desplegando cualquier estrategia, método y material empírico que tenga a mano. La materia con la cual se forma el bricolaje se compone de discursos o conjuntos de signos que confluyen en torno al tema de interés. Lo interesante de esta propuesta metodológica es que permite tomar como recurso distintos tipos de artefactos culturales como la danza, la escritura, las entrevistas y los registros fílmicos; lo que viene a ser un grupo de imágenes o retazos del bricolaje.

Recalcamos, como punto de partida de la metodología, la mirada sobre el objeto de estudio que brinda el marco teórico; los textos artísticos no son un objeto vacío e inerte, ya que se nutren y están marcados por lo subjetivo (Poe, 2007; Murillo, 2010; Grossman, 2011). En el caso de la danza, el movimiento también es lenguaje, discurso y texto, compuesto por elementos con posibilidad de ser leídos (Volosín, 2002; Hounie, 2014; Mariscotti, 2013) y; como se abordó anteriormente, se pondrá especial atención en el papel de la nostalgia, el duelo y su relación con la creación artística como eventual motor de la misma (Poe, 2010; Molina, 2010).

Por otro lado, las preguntas clave de lo metodológico giran en torno a la elección de los elementos de análisis dentro del proceso y las obras: ¿cómo elegirlos?, ¿cómo resolver su carácter consciente o inconsciente?, ¿cómo reconocer si un elemento responde a la subjetividad del autor o del lector? En respuesta a estas interrogantes, la elección de los elementos fundamentales consistió en la identificación de detalles sobresalientes y patrones constituyentes; en el caso de la literatura: palabras, temas, ideas centrales, figuras literarias, formas de puntuación y contradicciones que puedan encontrarse de forma repetitiva o insistente, ya sea de manera directa o "indirecta" en las obras. En el caso de la danza, implica identificar movimientos -pero sobre todo de formas de moverse-, desplazamientos, intenciones, gestos y cambios en la gestualidad y en la utilización corporal conforme transcurren las sesiones del taller, metáforas corporales y otros elementos correspondientes a la puesta en escena, que hayan sido expresados de forma intencional o "casual" en la construcción de las coreografías.

Se llevó a cabo un proceso minucioso de organización de datos con el fin de construir las diferentes unidades de análisis, realizar una codificación de patrones y categorías, mediante una tabla que enlistó y clasificó los detalles y patrones según temas e interrogantes. Dicho vaciado de información y su posterior categorización se retoma en el análisis como temas fundamentales. Se tomaron las frases compuestas de letras y de movimiento, así como los montajes y escritos en su totalidad, analizándolos por partes, así como sugiere hacer Bersani (2011) con los textos9, interesándose en la forma en que están organizados, es decir, su distribución estética, pero también en su estructura argumentativa, la distribución de las temáticas y mostrando el acento en las repeticiones, como ya ha sido mencionado.

El soporte en la elección de los ejes temáticos estará correlacionada no solo en la teoría, sino que tendrá mayor peso lo que ha sido dicho -la forma en que se dijo y las dificultades para decirlo- por las personas adolescentes durante las discusiones, en donde comentaban temas relacionados a los intereses, preocupaciones e ilusiones que buscaban plasmar en sus obras. Lo anterior estaría muy acorde con lo que propone Poe (2013) sobre un modo de lectura que presta atención a lo aparentemente nimio como “... los silencios, los lapsus, los olvidos, es decir, a todo aquello que hace trastabillar al discurso" (p. 13); todo esto sin afán de hacer una aplicación de teoría psicoanalítica, sino de encontrar correspondencias entre teoría y obra.

9 Porque como se ha explicado con anterioridad, partimos del hecho de que el cuerpo se asemeja a un lienzo y que el movimiento sería un texto, por ende la coreo-grafía, como lo menciona Mejía (2014) “... en el montaje puede producir una orto-grafía singular...” (p. 152). 
En el caso específico de la danza, esa segunda parte del proceso investigativo que incluye lo dicho sobre lo bailado, responde a la consideración de la coreografía como un signo de una escritura posible, que como bien lo señala Mejía (2014) “... para ser signo (trazo coreográfico), tiene que articularse con otro signo en otra escritura" (p. 152). Y es aquí, en la lectura psicoanalítica donde se busca articular y dar espacio para que aparezcan dichos signos.

Además, para la lectura de estos elementos en el texto escrito y danzado seguiremos ciertas sugerencias de la propuesta de Solano (1991), quien propone que no se debe presuponer un sentido y sostenerlo como discurso verdadero, sino establecer un diálogo con la obra y nunca explicarla por un discurso exterior, ya que: “... la naturaleza y alcances de estas lecturas psicoanalíticas: más que explicar, pretende preguntar; más que hablar del texto; persigue hablar con él, dejarlo hablar; más que darle un sentido, intenta seguir el sentido hacia el cual apunta” (p. 32).

Por lo tanto, una lectura psicoanalítica de un texto (escrito o corporal), debe analizar no solo lo dicho, sino lo no dicho, lo poco común, las anomalías del discurso; fijarse en el detalle que marca el inicio de una interpretación: “... un detalle es un significante que pone en acción una producción de saber ... construye una telaraña a partir de la ignorancia” (Solano, 1991, p. 70). El lector y el espectador, son un elemento activo, quien lee y mira afecta a la obra y se deja tocar por esta; es un productor de entendimiento y un significador.
Por su parte, Ioskyn (2013) plantea que lo esencial para un análisis psicoanalítico de lo literario es la localización de algo que funcione en tanto sujeto del inconsciente: “... el lector es quien crea al sujeto, lo ubica, lo localiza ... El sujeto es en definitiva, la sumatoria de ciertas frases o significantes escogidos, que dan cuenta de la lógica de la obra, con el agregado de la interpretación del lector" (Ioskyn, p. 32).

En este sentido, las propuestas anteriores plantean una incógnita que no se puede pasar por alto, el papel del lector y espectador en la lectura propuesta, ya que, a pesar de que las creaciones vengan desde las personas jóvenes y se intente en la medida de lo posible afirmar los elementos de análisis desde lo que plantean en su proceso creativo, en toda metodología el investigador es un ente activo e implicado.

Puede parecer contradictorio dar tanto valor al lector cuando lo que más importa es lo que expone el autor, no obstante, se debe tener presente que esa relevancia es a nivel de lectura y que hay una noción de un lector "preparado" y dentro de esa preparación debe prevalecer el permitirle al texto hablar por sí mismo, dejar que el movimiento y lo escrito sean quienes guíen el trazo del boceto y que el lector aporte su enfoque, su mirada atenta y su capacidad de análisis para poder retratar lo más fiel posible, no una copia exacta, sino la esencia de lo que constituye aquello que tiene ante sus ojos. A continuación, se presenta un esquema que sintetiza los procedimientos en cada una de las fases de análisis y de consecución del material analizado:

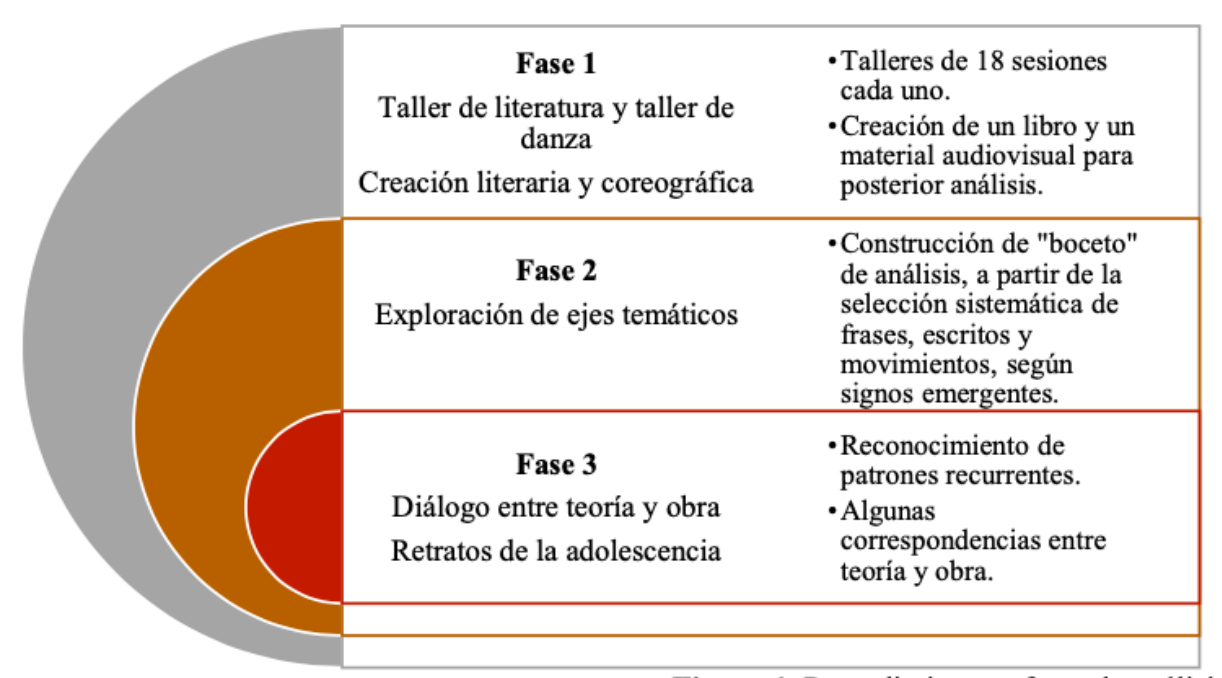

Figura 1. Procedimiento y fases de análisis. 


\section{Análisis \\ 5.1. Sobre el papel: descripción de los talleres de literatura}

En el caso de las personas jóvenes del taller de literatura, el motivo para participar fue muy variado: querer escribir un libro, acercarse a un pasatiempo o, simplemente, conocer gente nueva. A pesar de la poca claridad en la respuesta del “ipor qué estoy aquí?”, hubo mucho acierto en las respuestas sobre lo que consideraban literatura y su función, señalando características asociadas al ámbito académico, el entretenimiento y la comunicación y, a la vez, profundizando en aristas ligadas a una función social: "Decir lo que no se dice por normas sociales, cambiar el mundo, concientizar ${ }^{10}$ ", "nos ayuda a recordar y no olvidar"; la expresión de sentimientos y opiniones: "Expresar sentimientos, dar una parte de uno"; o como acto catártico: "desahogarse cuando uno está a punto de estallar", "un libro es un amigo; uno escribe lo que siente, le cuenta y no es juzgado, es algo que solo queda entre el lápiz, el papel y uno".

En cuanto a los ejes de escritura y discusión, las personas adolescentes construyeron su espacio con temas relacionados a recuerdos de la niñez, lo positivo y negativo de la familia, la diversidad, los temas tabú, el amor (desamor, ambivalencia), el uso de drogas, la confusión en la adolescencia, las contradicciones y miedos del ser humano, el sentido de la vida y la muerte, temas mitológicos e históricos. Ante la constante crítica de la sociedad actual, una de las jóvenes afirma: "Todas queremos hacer crítica de la sociedad, es algo más adolescente, los adultos no se quejan, les da pena”.

Hay una reflexión profunda en cuanto a la relación entre lo que se escribe, el acto catártico y de reconstrucción subjetiva, destacando la escritura como un lugar propio y seguro: "Suelo escribir triste, es una forma de expresar lo que siento, porque si lo dijera me llevarían a terapia”. También, una de las participantes hace un importante enlace de la escritura con la posibilidad de ser y construirse: "Soy cínica, así están las cosas, escribo pesimista ... tengo 15 años, no puedo derrocar a nadie, no puedo decir mis cosas, entonces escribo ... mis sueños, mis miedos se convirtieron en escritura".

Al finalizar el proceso, las personas participantes hicieron una última reflexión sobre su pasaje por ese espacio, posicionándose ante la escritura como algo que quisieran mantener como pasatiempo o profesión, no necesariamente ligado al dolor y la tristeza. Una de ellas concluye sobre la relación de la escritura y la adolescencia: "nos da voz, y una oportunidad de comprobar que no solo somos rebeldes y suicidas".

\subsection{Sobre las tablas: descripción de los talleres de danza}

Desde el comienzo de las sesiones de danza, llamó la atención el anhelo de las personas participantes por experimentar en esta disciplina, pues no fueron pocos los comentarios acerca de la "meta frustrada" de ser bailarín o bailarina, de las clases que alguna vez iniciaron, pero no pudieran continuar por asuntos económicos o por no encontrar apoyo para aprender algo de la danza contemporánea. De igual forma, un común denominador fue la nula experiencia en este arte, aunque una de las participantes menciona que se trata de "decir sin palabras".

Una vez en acción, aún con su deseo de danzar, las personas adolescentes mostraron con sus cuerpos lo que pareciera contradecir a sus palabras: miedo de moverse, vergüenza de sus cuerpos y de sus propios movimientos: "no conocemos nuestro cuerpo"; cuerpos acostumbrados a otro uso, específicamente el del cuerpo sentado; muy practicado en su vida académica. Esto aunado a una incomodidad producto de las miradas del otro, la mirada entre ellas y ellos hacia sus cuerpos en movimiento.

10 Todas las comunicaciones personales dentro de los talleres se presentarán entre comillas, haciendo alusión a lo dicho de forma literal por las personas participantes, sin embargo, no se indicarán nombres ni se hará uso de seudónimos, debido a que el interés no está en el estudio de un caso o casos en particular, sino en mostrar las frases principales que componen el "boceto" que se fue construyendo como material de lectura y análisis. 
Lo anterior, lejos de ser una limitante para el taller de danza, fue motor para que los cambios fueran más evidentes. Así, por ejemplo, sumergirse en la práctica de la observación del propio cuerpo y del cuerpo del otro les permitió una mayor conciencia de su postura y les llevó incluso a preguntarse por la razón de su forma de caminar y lo que reflejaban las posturas de sus compañeras y compañeros de colegio: "se ven enojados", "cansados", "obstinados", "amargados", "con el cuerpo tenso".

La inhibición también se fue perdiendo conforme se hacían intervenciones, ya fuera con indicaciones breves, con la utilización del espejo, con una palabra para transmitir una sensación, pero sobre todo con la utilización de las manos como guía mientras se realizaba algún movimiento: "se siente más el cuerpo", "es como profundo", "se tiene más control sobre sí mismo", "el cuerpo más suelto", "lo percibo más sensible”.

Los ejercicios en colectivo fueron generando más confianza y fluidez, aunque los resultados positivos no se daban si los subgrupos eran grandes, sino en ejercicios de parejas o tríos, como si existiera la necesidad de mantener una comunicación más íntima con el cuerpo del otro para moverse en conjunto e incluso para que se diera una coordinación totalmente inconsciente: "yo nada más lo sentí", "no me di cuenta que lo hicimos igual", "coordinamos, pero no hablamos para ponernos de acuerdo".

Algunos de los cambios más significativos, a lo largo de las sesiones, fueron: una dinámica de inclusión mayor de las personas participantes que se mostraban inhibidas a la hora de moverse; el descubrimiento de nuevas formas de moverse que les motivaba a practicar en los recreos del colegio y desafiarse; el aprovechamiento de los minutos de descanso para utilizar la barra de ballet (con la que no cuentan en ningún otro lugar); algunas personas participantes que se ocultaban detrás de las demás, o escogían las esquinas, comenzaron a salirse de esta zona para apropiarse de su espacio y de su cuerpo. A su vez, personas participantes que en los momentos de improvisación se quedaban estáticas o movían únicamente los dedos de sus manos, llegaron a aportar movimientos a las coreografías finales e interpretaron solos $^{11}$, dejando atrás la vergüenza e inseguridad que limitaba al cuerpo.

De este modo, se podría pensar en un requerir del acto de creación para adueñarse de los movimientos, incluso para mirar en lo todavía no existente o en lo aún no muy elaborado sobre sí, al mismo tiempo que se construía una coreografía con el fin de extender el imaginario individual y social.

\subsection{Lo escrito}

Durante el proceso de los talleres se construyeron muchos textos, de los cuales se eligieron nueve escritos por 3 de las participantes para ser presentados en la muestra Corpografías y ser impresos en el libro-memoria del taller. Dichos textos fueron discutidos y trabajados con especial dedicación, ya que representaban sus obras más significativas. Seguidamente, se analizan los aspectos esenciales que se conjugan en (y entre) estas creaciones:

a) La búsqueda de sí en la palabra propia

El primer tema que sobresale es el uso de la palabra como determinante de sí. El texto Palabras hace obvia desde la inocencia de una niña, la relación entre la palabra y el ocupar un lugar en el mundo (o hacerse un lugar en él), así como la importancia de la voz propia y la escritura como medio de expresión. La posibilidad de ser alguien se construye desde el uso de la palabra por lo que el mayor castigo en el relato es el que le quiten el derecho a usarlas (tal como lo hace la madre de la niña).

En esta misma línea, 100\% algodón, nos plantea la lucha por la consolidación de sí desde la defensa del pensar y de la opinión propia. El cuento narra la historia de una ciudad perfecta, perfección que se obtiene gracias a un ritual por el que pasan todos las personas jóvenes al cumplir los 18 años, sembrándoles una semilla de algodón en la cabeza: "Una vez que los chicos son puro algodón se pueden unir a la ciudad perfecta, pues, ¿quién puede

11 Secuencia de danza o segmento interpretado de forma individual. 
pensar cosas malas estando lleno de algodón12?”La protagonista de la historia se plantea como una primera disidente del sistema, quien renuncia a la perfección a cambio del derecho a pensar.

En este texto surge la intromisión de los otros en la construcción de sí: "Pero todos en su bella ciudad estaban rellenos, ¿qué pensarán de ella?”; tema que se repite en Sakura: "¿Al fin dejaré esta soledad que me aprisiona? ¿Acaso me aceptarán? ¿Me verán hermosa?”. Este es de suma importancia, porque el papel del otro puede venir a consolidar al sujeto o a debilitar la construcción de sí mismo y la palabra propia.

b) Ser o morir frente al espejo de la soledad

La pregunta sobre sí parece la más importante para la vida, esa pregunta que se dirige hacia sí mismo o se le hace a los otros que se toman como reflejo para la constitución de una identidad. Reflejo, se centra en la pregunta “¿quién soy?", un sujeto frente a un espejo se cuestiona sobre lo confiable que puede ser su propio reflejo, conversa con él buscando concretar algo de sí.

Tanto en este microrrelato como en Sakura y 2:0o a.m., el espacio de la soledad aparece como un lugar de incertidumbre, un tiempo de introspección para pensarse, que aún en la monotonía, hace que ocurran cosas importantes para quien se piensa. Desde estos textos se entiende que si esta pregunta obtiene una respuesta con tintes de decepción o fracaso ("Esa era yo, un cuerpo sin vida yendo a un futuro desconocido"), la incógnita migrará hacia la pregunta sobre la vida y la muerte ("ojalá pudiera abrir mis alas y desvanecerme entre las nubes”).

Esta incógnita entre la vida y la muerte aparece en los escritos frente a un reflejo; en una madre que teje, en una ventana o en la imagen de un otro: “Qué pasó aquí? ¿Por qué me veo diferente si nací de la misma semilla? ¿Acaso eso es malo? ¿Hay algo malo en mí? ¿Acaso no pertenezco a aquí?". El riesgo de no atender a la pregunta “¿Puedo ser confiable a la hora de reflejarte?”, es el de no diferenciar qué tanto de eso que compone el reflejo es propio o viene de un discurso externo.

La respuesta en Reflejo ("Eso depende de ti"), es la clave para que siempre haya un posicionamiento de algo propio que permita perdurar: "ya no soy la misma flor del capullo que brotó en aquella fría madrugada. Me aprecio como soy por dentro, no por lo que aparento". Se muestra un retorno al sí mismo y a la posibilidad de decirse, nombrarse; ocupando así, un lugar distinto al "destinado".

c) No tener palabra es no tener poder

En relación a lo anterior, los textos sugieren que el mayor peligro ante la vida no es la muerte, sino el no tener palabra, por tanto, estar dominados por el discurso y el poder de otros. Ceder la palabra implica la opción del silencio y la ignorancia, conformarse con ser parte de un sistema, abandonar la posibilidad de construirse en diferencia, tal como se plantea en Sakura: "Todos tienen algo en común; el sentimiento de la soledad, el temor de enfrentar a la muerte sin haber conseguido amor o aprecio o hasta sin tener una liberación".

También, los textos Estallido y ¿Cómo se tragaron el mundo?, nos retratan con violencia el abuso del poder, la imposibilidad de defenderse, pero, ante todo, el papel pasivo que nos lleva a elegir líderes cobardes e incluso la cuerda con cual ahorcarse: "Ese es mi truco ¿Sabes? Que caben su propia vida, su propia tumba”.

Este eje fue insistente en muchos de los trabajos realizados en los talleres, cargado en su esencia de crítica social, de un reclamo hacia lo que han hecho las líderes y los líderes del mundo, hay en estos escritos un acto de rebeldía, deseo de separación y de enfrentamiento no solo contra aquellos que se han "comido el mundo", sino contra aquellos que no han hecho nada; así como lo explica una de las autoras: “... nos hemos dejado tragar demasiado por el miedo: a ser superado, miedo a ser eliminado, miedo a ser olvidado. Eso nos ha arruinado la experiencia de todo. Porque el miedo con medida previene, al extremo corrompe como óxido y daña todo lo que toca”.

12 Las frases entre comillas y en cursiva corresponden a fragmentos de los textos construidos por las personas adolescentes. Se señala en el análisis, a cuál escrito pertenece cada una de las frases destacadas. 
d) El personaje femenino

Una de las principales particularidades de estos textos es haber sido construidos solo por mujeres, lo que puede explicar por qué la mayor parte de los personajes tengan una voz femenina. Como hemos visto en los puntos anteriores, estas voces están ligadas a cierta angustia y confusión y a la búsqueda del sí (que se puede generalizar a la adolescencia), a pesar de conseguir cierta determinación en sus acciones. De ninguna manera se quiere asociar lo femenino a lo débil y temeroso, empero se debe subrayar que hay un guiño al alejarse de ciertos estereotipos ligados a la feminidad, por ejemplo, en $100 \%$ algodón donde la protagonista sostiene su renuencia a ser parte de esa sociedad "perfecta", porque implica ser suave (al igual que su madre que teje sweaters) y a ella le gusta saltar en charcos y tener opiniones propias.

En Diana, esta figura femenina asociada a la luna, lucha contra una generalización de la feminidad sufrida y que espera, que no puede escapar de las ataduras en una relación afectiva, aquí la voz femenina sufre. Contradictoriamente, también sufre la voz femenina más fuerte de todos los escritos, Cleopatra, representada en Decaída, se nos presenta como una mujer poderosa, inteligente y determinada, sin embargo; de algún modo su logro de sobrepasar los estereotipos femeninos la condenan en un lugar de soledad e incomprensión.

e) e. El amor

A pesar de no ser un tema que ocupe un lugar privilegiado en la elección de los textos finales, lo cual ya nos habla de una ruptura de la idea de asociar la escritura femenina a los textos románticos; el amor y el desamor sí fueron temas que se abordaron en el espacio de creación, donde se vinculó a la ilusión y la felicidad, pero también a la ruptura y la enfermedad. En los textos elegidos sobrevive una referencia en el texto Decaída en el que la protagonista asegura ser capaz de amar "Con locura y sin ninguna censura" y en Diana, donde se resalta la imposibilidad de la ruptura, la repetición del amor como condena, describiéndolo como una emoción que va más allá de los deseos propios y la razón.

\subsection{Lo danzado}

El proceso de las sesiones de danza, incluyó espacios de ejecución de técnicas, improvisación, observación, reflexión sobre el movimiento, exploración del cuerpo y sus posibilidades, así como importantes espacios de escucha. De la creación de obras surgieron discusiones y de las discusiones, las obras principales de la muestra final. En ocasiones, la "simple" puesta en escena de una frase de danza, creada a partir de una imagen, de una idea, de una música, les provocaba palabras sobre lo bailado. Es a partir de este método que surgen los siguientes ejes temáticos, destacados tanto en las producciones individuales como colectivas:

\section{a) La búsqueda de una identidad}

No ocurrió sola una vez, el no sentirse apto o apta para moverse de una determinada forma o incluso el no sentirse invitado o invitada al grupo que se encontraba improvisando en el centro del salón: "Me daba vergüenza todo, no me metía al círculo por vergüenza", "no sentí nunca que tenía que entrar". Tampoco fue inusual la dificultad que se sentía ante una propuesta dancística en la que no mediara una guía escrita y clara de cómo moverse, por lo que se recurría a mirar a otros para encontrar allí la guía. En este sentido, impresiona la siguiente explicación de uno de los participantes ante la consigna de caminar libremente por el salón: "El primer impulso fue caminar en línea recta, todos lo hicimos así, seguro porque estamos esperando a alguien que nos diga qué hacer y estamos acostumbrados a copiar a los demás".

Que lo común sea caminar en línea recta, nos habla de una normativización del movimiento, un movimiento "ordenado", en todo el sentido de la palabra. Pero para adicionar complejidad al tema de la búsqueda de una identidad, también habría que decir que quienes se mostraban más libres en su movimiento y en la improvisación, en ocasiones mantenían una mirada que solicitaba una felicitación, sin que desapareciera así el fantasma de lo que se considera "bonito" o "feo" como limitante a la hora de crear. De igual forma, "lo correcto" hizo sombra en lo danzado; pero más que lo "correcto", la culpa por no serlo, ya sea por no cumplir expectativas 
ajenas, por no ser "suficiente" y/o por "fallar" en los distintos ámbitos de sus vidas.

La ausencia de un espacio para pensarlo, la culpa por no sentirse capaz y la crítica propia y externa, hacen mella en esa búsqueda de una identidad. Hay que señalar que la crítica externa no solamente es la familiar, sino la del grupo de pares. En esta misma línea surge el asunto de la discriminación por la condición socioeconómica: "cuando uno no se viste charral le dicen Bajo Zúñiga, Llano Brenes, que son barrios bajos", "se juzga por lo que ven por fuera y no por lo de adentro, no por lo que soy, aunque yo ni siquiera sé cómo soy", "la pobreza no es mi culpa, es culpa del Estado". Esto fue trabajado en la obra Desafortunado ${ }^{13}$ de la que se hablará más adelante.

Ahora bien, otro componente que salió a relucir fue el de los estereotipos de género y orientación sexual, tanto en el discurso como en el baile mismo. Por ejemplo, a algunas personas adolescentes se les dificultó asumirse como partícipes de un taller de danza pues a "los hombres no les gusta la danza", "eso es de mujeres". Estos estereotipos también se hicieron evidentes en la presencia mayoritaria de mujeres (9 mujeres y 2 hombres), en la retirada de algunos hombres a mitad del proceso y en la precaución de los hombres para no ver su "masculinidad" comprometida. En el discurso, sin embargo, se halla lo siguiente: "tenemos compañeros en el colegio muy machistas y que piensan que no pueden expresar lo que sienten por ser hombres", "por qué se tienen que meter con las personas homosexuales, son personas que solo están experimentando sentimientos igual que uno", "influyen mucho las personas, el qué dirán o qué piensan de mí”.

Así, estereotipos, mandatos sociales, pertenencia a una clase social, condición socioeconómica, expectativas familiares y la ausencia de espacios para la exploración propia, se volvieron fichas fundamentales para hablar de la búsqueda incesante de la identidad en este grupo de adolescentes. b) Entre la vida y la muerte

"Es que no todo es rosado", explica una de las participantes cuando eligen montar la coreografía Desafortunado que trata la temática de la muerte, el suicidio y la tragedia con que dicen, suelen vincular; pero también eligen estos temas, debido a los actos cercanos a la muerte que escuchan en sus conversaciones diarias, los motivos y las historias de vida que tienen como desenlace una tragedia y aquello que ha pasado por sus pensamientos cuando, paradójicamente, se preguntan por la vida. Dicen entender a quienes piensan que la muerte es una alternativa, pues hay situaciones "que nos ponen mal y a veces no hay otra solución”. Explican que algunos actos contra sí se deben no solo al sufrimiento por algún acontecimiento, sino por el aborrecimiento al propio cuerpo, al no considerársele bello. Al mismo tiempo manifiestan un miedo a la muerte, pero no a la propia sino a la de los otros.

Otro punto interesante al respecto es cuando enfatizaron que "la muerte es como dormir; no se sabe qué pasó". De ahí el enlace entre las obras Desafortunado y No me acuerdo; el lazo se da, principalmente, en los movimientos elegidos y las secuencias bailadas, siendo la segunda la obra más "sentida", eligiendo para esta, música instrumental y teniendo como base el acto del dormir, el sueño como acto de reposo, pero también los sueños como lo anhelado, la nostalgia y el despertar. Los movimientos elegidos, en general, daban la sensación de lo liviano, lo etéreo, pero también de lo doloroso y la impotencia ${ }^{14}$.

Diferente a Desafortunado, donde eligen movimientos bruscos, gestos vinculados al enojo, a la frustración, lo que da pie a que se volviera una obra con tinte más político y de crítica social. Este giro que dio la obra, que comenzó siendo sobre la tragedia propia e incluso el suicidio, se debe a opiniones como la siguiente: "de pequeña no pensé tanto en la muerte pero ya más vieja me canso de la vida”, haciendo referencia a las vicisitudes de su cotidianidad, a las demandas de su familia; "da miedo fracasar, el olvido de la familia, que algún día dejen de quererme, son miedos

13 La crítica política y social fue una constante tanto en el trabajo en los talleres de danza como en los de escritura, al punto que al mostrarse los trabajos entre los grupos de literatura y de danza, ambos deciden presentar la obra Desafortunado, con una interrupción por parte de una de las participantes del grupo de literatura, quién leería el escrito ¿Cómo se tragaron al mundo?

14 Cabe resaltar que parte del público que presenció esta obra manifestó su conmoción por el afecto que les transmitía, entre dolor y calma. 
de la edad, miedo a no cumplir"; y a sus dificultades académicas e incluso económicas: "no es malo soñar, lo malo es la necesidad de recursos para cumplirlos". Esto fue discutido ampliamente con un interés especial de expresarlo con la danza y en mostrar agobio.

\section{c) La pérdida}

No tan desligado del tema anterior, se encuentra la cuestión de la pérdida. Fue el tema principal de la obra Espiral, donde se abordó el amor, el desamor y la soledad, pero al mismo tiempo el amor y los ciclos de vida que vienen acompañados de repeticiones, de encuentros y despedidas. En esto resultó la obra finalmente, no obstante, el desarrollo de la misma inició por el tema de la pérdida "amorosa", aquella que puede ser la "de un pariente, una amistad, no es solo de pareja”. En alguna de las sesiones, se les solicitó a las personas adolescentes que llevaran un objeto importante para ellas con el fin de utilizarlo como elemento desde el cual se desprendería un relato, un discurso, una composición que utilizara el lenguaje de la danza. Los objetos llevados remitían a la infancia, pero sobre todo a la infancia perdida: peluches, collares que les habían heredado en su niñez, fotografías de la infancia, regalos de sus padres o hermanos cuando eran menores. Ningún objeto se había obtenido en los años que llevaban siendo adolescentes.

Lo que crearon, a partir de los objetos, fueron pequeñas coreografías que trataban sobre el miedo de crecer y el tener que resolver en solitario los "corazones rotos", los ciclos de vida (el terminar y el iniciar), el reloj(tiempo), lo que se acabó y el "no te vayas", el despedirse, la "felicidad por lo que va a venir y la tristeza por lo que hay que dejar", las pesadillas y la añoranza. El tono, cuando se hablaba o se bailaba sobre las pérdidas, siempre fue un tono decaído y vislumbrando en nostalgia. Poe (2007a) comprende la producción que se basa en la rememoración y el "... volver la mirada sobre la propia vida” (p. 100) como una tarea que viene acompañada de tristeza; “... como si abismarse en la interioridad constituyera una empresa tan peligrosa como un viaje al hades que transforma al viajero y lo enfrenta con sus muertos" (p. 100).

\section{Discusión}

Este recorrido revela una serie de puntos de vista e interrogantes que permiten pensar la adolescencia y lo que ya se ha escrito sobre ella. Por lo que se consideran como los principales aportes de esta lectura psicoanalítica; por un lado, brindar una visión de la adolescencia y del entorno que la envuelve desde los procesos creativos de un grupo de jóvenes y, por otro lado, el abrir un diálogo con la teoría, sin buscar que una calce en la otra, sino complementándolas en su discurso.

En la totalidad de obras creadas (tanto escritas como coreográficas), se presentan cuestionamientos que han sido abordados históricamente en el estudio de la adolescencia. Entre estos temas se encuentran: la relación del adolescente con la sociedad, la construcción de una identidad social vs. una identidad individual, el "trabajo" en la adolescencia por encontrar el significante propio y, la relación con la tragedia, la pérdida y la muerte en este período de la vida.

Uno de los grandes teóricos del desarrollo es Erik H. Erikson (1978), quien profundiza en la relación entre el individuo y su medio social. Este autor le da especial importancia a la construcción de la identidad y a lo que él llama la "crisis de la identidad"; sostiene que esta "crisis" tendrá lugar según las características del medio, el momento histórico-cultural, clase social, o historia personal; planteándolo incluso como un "segundo nacimiento".

Para Erikson (1968), la persona joven siente una continuidad entre lo que se ha convertido en los años de infancia y lo que promete devenir, entre lo que busca ser y aquello que los otros esperan. Esta "crisis" no será resuelta hasta construir identificaciones con los pares u otros que no pertenezcan a la esfera familiar.

Estas afirmaciones nos plantean un problema a la luz de los resultados arrojados en la presente investigación, pues ¿qué pasa cuando ese grupo de pares que encaminará a la conformación de una identidad, ese grupo de pares que representa el afuera, la "salida" del hogar, es el representante de la exclusión? Una exclusión que 
se da por la clase social y la condición socioeconómica o por el cuerpo que se tiene o no se tiene. ¿Qué pasa entonces cuando lo que permitiría "salir" da la espalda? $\mathrm{o}$ ¿qué sucede cuando lo que promete devenir parece que quedará en promesa, debido a las condiciones sociales? A estos elementos conflictivos, expuestos por las personas participantes, podemos añadir también las expectativas familiares que tanto mencionaron y de las que pareciera, están lejos de desmontar.

Freud (1929) argumenta que frente al dolor y la angustia de la existencia ${ }^{15}$ se necesitan "calmantes" y, precisamente, la sublimación de las pulsiones en el arte sería un método para la evitación del displacer, pero diríamos que también podría percibirse como un método que produce placer per se, antes que una mera evitación. Es aquí donde toma relevancia la escritura de sí y la creación propia, así como poner el cuerpo para escribir justo allí donde se posaron las miradas discriminatorias alguna vez; sin afán de que algo de esto produzca una resolución, pero sí un tramitar distinto o inclusive un acercamiento a una eventual salida ante tanta frustración.

Erikson (1978) expone que la búsqueda de sí mismo tiene un aspecto social porque el universo social compartido es el medio ambiente del ser humano, el cual confiere una ritualización que indica a las personas adolescentes el camino hacia la identidad:

... la juventud, en particular, depende de la coherencia ideológica del que se supone debe hacerse cargo, y en consecuencia se da perfecta cuenta de si el sistema es lo suficientemente fuerte en su forma tradicional como para ser "confirmado" por el proceso de identidad o está lo suficientemente debilitado como para sugerir su renovación. (p. 12).

En este sentido, Erikson (1978) plantea que "Las acciones de los jóvenes son siempre, en parte y por necesidad, reacciones a los estereotipos sostenidos frente a ellos por sus mayores."(p. 161). En relación a las obras artísticas, se puede entender la "rebeldía" y la crítica social, como un espacio para dejar evidencia de ese disgusto con la propuesta política, al no verse reflejado en una sociedad compuesta de exigencias que ellas y ellos no pidieron y miedos que les son incrustados como requisito para ser parte de la "masa exitosa". En 100\% algodón se ejemplifica el ritual social que "invita" al adolescente a renunciar a una parte de sí, sustituyéndola con una alternativa social que le "ahorre" el pensar. Del mismo modo, en Sakura y en la coreografía No me acuerdo, hay una lucha por construirse a sí mismo en contra de la exigencia de otros, un conflicto entre ser quien se quiere y ser quien otros esperan.

En esta misma línea, Blos (1986) plantea que la adolescencia es la suma de intentos de la persona adolescente para ajustarse al nuevo grupo de condiciones internas y externas que conforman el individuo; intentos que se caracterizan por la experimentación, la resistencia, la rebeldía y la oposición; acompañados de sentimientos de aislamiento, soledad y confusión. Obras como Diana, Espiral, No me acuerdo y Sakura, incluyen estos elementos, pero más allá de una angustia en su totalidad, en las preguntas del ¿`ser o no ser? o ¿cómo me verán otros?, hay una insistencia en la búsqueda de respuesta y no en la paralización. La confusión, la ambivalencia y la contradicción endosadas a las personas jóvenes puede que sean una más de esas palabras que sirven para señalar la adolescencia, cuando en realidad, estas no son exclusivas de una etapa de vida; asumiendo que la adolescencia se puede definir como una etapa, cuando en realidad podría componerse de momentos varios de la vida de un sujeto, sin que lo fundamental para definirla sea un lapso de edad.

Por otra parte, Firpo, Lassalle, Ortega, Díaz, Prates y Sansarricq (2000) plantean que el sujeto no soporta pasivamente los significantes que vienen del Otro y que lo buscan determinar; en la adolescencia esos significantes, se mueven, se tambalean: "todo ese revuelo de significantes en el que se inserta activamente el sujeto, será replanteado en la adolescencia ... el niño

\footnotetext{
15 Dicho sea de paso, el tema de la existencia se bordea en los resultados, en el sentido de que ante circunstancias adversar como las planteadas, podría requerirse que se asuma la culpa para poder existir, la culpa por "fallar", la culpa por no seguir las normas, la culpa por distanciarse de las expectativas ajenas, la culpa por existir.
} 
y el adolescente están en un tramo de producirse como sujetos" (p. 51). Es decir, hay una posibilidad de tener voz y demostrar que la adolescencia - como lo plantea una de las participantes- no es solo rebeldía y suicidio.

Esta producción de sí mismos responde a trabajos simbólicos: “... se relaciona el trabajo con el proceso de ligar, desligar y volver a ligar de un modo distinto" (Firpo, Lassalle, Ortega, Díaz, Prates y Sansarricq, 2000, p.117). Por tanto, se confirman aquellas voces que, desde la producción artística, encuentran nuevas formas de decir; lo expresado en el texto Palabras y 100\% algodón, así como en la coreografía No me acuerdo, donde se expone este proceso creativo que, a la vez, es la búsqueda de la palabra propia y el desmarcarse de la palabra del otro.

Enlazado a esto, Firpo, Lassalle, Ortega, Díaz, Prates y Sansarricq (2000) exponen que el arte es un medio para lograr dicho trabajo, ya que: "El arte no se contenta con adornar, con ilustrar, realmente organiza" (p. 117). Este trabajo es enfático en no presentar el arte como "la cura", sino como el espacio para retomar y para inclusive atender un asunto. Por ejemplo, con respecto a la nostalgia y a la pérdida, tanto en la teoría como en las construcciones de las personas adolescentes, donde fue palpable cómo aquello vinculado a la pérdida, tuvo un lugar predominante y cómo en Espiral se intentó llegar por medio de la puesta en escena de un ciclo, de varias vueltas sobre un mismo punto, a través del movimiento repetitivo, a la pérdida del otro, a la pérdida de la niñez y a lo que se perdió con ella. Al emprender su trabajo sobre el duelo, Allouch (1995) enuncia que “... el sujeto habrá perdido entonces no solamente a alguien sino, además, sino, aparte, sino, como suplemento, un pequeño trozo de sí” (p. 30o). Ese trozo de sí, que tanta angustia parece provocar en las personas adolescentes, tal como se mostró en el análisis de las obras. Al mismo tiempo, y de forma coincidente con la propuesta dancística de Espiral, Allouch (1995) afirma que ante el duelo:

... no hay objeto sustitutivo por la razón esencial de que el objeto de amor no es situado por el recuerdo, sino por la repetición, y lo que cuenta en la repetición es justamente la cuenta, la imposibilidad para la segunda vez de ser la primera - aun cuando se la pretenda en todo idéntica a la primera. La cuenta, por sí sola, inscribe como esencial la no-sustituibilidad del objeto (p.163).

Esto trae a colación la sublimación como ese aprovechamiento de los impulsos susceptibles de transformarse en fuerzas creadoras: "Las creaciones realzan los sentimientos de identificación que tanto necesita todo círculo cultural; lo consiguen dando ocasión a vivenciar en común sensaciones muy estimadas" (Freud, 1927, p.13)

Por su parte, Fernández (1999) retoma la relación de la adolescencia con la cultura, y resalta el carácter de actividad del adolescente, una actividad dirigida en un tú a tú: "la relación de la adolescencia con la cultura es "esencial" ... [adolescencia] es ... el nombre de este movimiento en que la cultura se hace reflexiva. Y [adolescente] es aquel que sostiene una pregunta a la ley que lo inscribe" (p. 245).

Al igual que los textos y las coreografías que definen la búsqueda y encuentro de algo propio, Fernández (1999) defiende que la esencia de la adolescencia está en decirse y que en ese encuentro con la palabra se permite el pasaje a otra cosa: “... la producción y circulación de la diferencia es algo que reconocemos en el acceso a un escenario que posibilite el encuentro con la propia palabra. El lenguaje es registro de la diferencia, en la palabra el sujeto construye su diferencia”. (p. 254).

Por su parte, Tubert (1982) expone que en la adolescencia hay una contradicción que aparece como tema central: “... la oposición entre la vida y la muerte, ya sea que estos significantes nos remitan a las pulsiones freudianas (gran modelo pulsional), a la progresión-regresión, a la integración-desintegración, a la síntesis-destrucción, al aparecer en el mundo-desaparecer de él, al crecimientoparálisis" (p. 19).

Más allá de una sola contradicción, los talleres y las obras, demuestran que el trabajo artístico de estas personas jóvenes se basa en el encuentro y confrontación de múltiples factores que se oponen: amor-desamor; vida- 
muerte; sueños-fracasos. Es por ende insuficiente la lectura simplista de la adolescencia como una época de confusión, dolorosa y trágica (y del arte dependiente de lo oscuro para mover el motor de la creación), ya que las personas adolescentes plantean en su obra el espacio apto para la de-construcción, re-construcción y transformación de los significantes, dejando de ver absolutismos y extremos en las palabras o los sentimientos.

Tubert (1982), añade que: "Frente a la muerte se experimenta un doble movimiento de angustia y atracción: aparecen en muchos casos las fantasías de suicidio, o las referencias a la muerte como un misterio que atrae y fascina” (p. 147). Sin embargo, consideramos que esta atracción y fascinación no es hacia la muerte como acto de darse muerte, sino como enigma que debe ser enfrentado para darle sentido a la vida. La pregunta sobre sí que no se responde (como lo vimos anteriormente ante el "reflejo") migra hacia la pregunta sobre la vida y la muerte, se intercambia la pregunta del ¿quién soy? por el ¿quiero ser? y los esbozos de la respuesta deberían devolver (si la apuesta es la vida) a la persona adolecente hacia el espejo, las tablas o el papel; para seguir preguntando y construyendo.

\section{Conclusiones}

El recorrido a través de la creación artística y de las principales huellas dentro de las obras creadas por las personas adolescentes de este proyecto, dibuja un boceto de algunos procesos que ayudan a pensar la construcción de sí, la búsqueda de la palabra propia o del propio movimiento y, la rebeldía como una forma de consolidar un espacio de pertenencia. De igual forma, surge el cuestionamiento al tema del dolor, la tragedia, la confusión y lo oscuro relacionado al arte y a la adolescencia, y la posibilidad de la creación artística como puente para trascender a "otra cosa".

Primero, se subraya el carácter de ambigüedad y confusión presentes en aquellas huellas que marcaron la escritura y el baile de estas personas jóvenes. Dichas huellas están presentes en las obras como elementos en disputa, elementos vivos que se construyen y se reconstruyen; por lo que no es acertada una noción negativa sobre la ambigüedad y la confusión, ya que son precisamente estas características las que permiten la búsqueda de la palabra y significación propia. Valga aclarar que esta búsqueda se hace en confrontación (en rebeldía necesaria) con un mundo adulto que impone formas de significar las cosas y que a su vez las personas adolescentes perciben como un mundo lleno de contradicciones, injusticias e hipocresía.

En relación con la pregunta sobre sí, la palabra propia es determinante del ser como marca de identidad y libertad; en la encrucijada frente a lo que llamamos "el espejo de la soledad”, aquel espacio en que surge la incógnita ¿quién soy?, esa pregunta que parece realizarse el sujeto a sí mismo, en realidad se la hace a un reflejo poco confiable compuesto por el discurso de otros. Si el reconocimiento en ese espejo trae una connotación de disconformidad con el ser, la siguiente incógnita empujará al sujeto hacia la pregunta por la vida y la muerte; solo la posibilidad del sujeto de poder decirse y de diferenciarse del discurso que le atrapa en el espejo permitirá la consolidación de sí en una voz propia y la posibilidad de continuar su camino hacia lo que venga, un nuevo espejo o el perdurar, alejándose de la idea de la muerte como una forma de diferenciación, aquella en que la palabra es de otro.

La idea de la consolidación del discurso propio también se puede observar en el tratamiento que las personas adolescentes hicieron del tema del amor y la presencia de lo femenino; en el primer caso, el triunfo ante las caídas y repeticiones amorosas, los ciclos destructivos, es la superación de la idea del amor sufrido como algo indomable, si bien es considerado un sentimiento sobre el cual no es fácil tener un control, la comprensión del mismo llega a ser una forma de triunfo del deseo propio. En el tema de lo femenino, la ruptura de estereotipos y mandatos de género conllevan a un señalamiento desde otros discursos, planteando un escenario conflictivo. El discurso externo castiga la consolidación de otra posibilidad para lo femenino.

Ante este panorama, el arte permite diferenciarse de lo externo y poder pasar a otra cosa. Esa otra cosa no es la adultez ni la madurez, sino un lugar donde se posibilita un encuentro con una imagen propia, donde se le puede dar sentido a la existencia y donde se pueden 
rechazar aquellos discursos que traen como bandera determinantes sociales ligados a la adolescencia: locos, rebeldes, depresivos, suicidas.

Por último, se resalta el valor investigativo del diálogo y la práctica interdisciplinaria, además de remarcar el valor de la "experiencia artística" como medio de expresión cultural y subjetiva; al mismo tiempo, se plantea la importancia de lo que tienen que decir las poblaciones sobre sí mismas y su entorno, en este caso las personas jóvenes.

La falta de espacios en que se le dé valor al discurso adolescente, en que se brinde un lugar al arte como posibilidad de construcción propia, colabora con conductas de aislamiento o "catárticas" que llevan a las personas adolescentes a sentirse mal o incluso a actuar de formas que atentan contra sí mismo u otros.

No es casual que en San Ramón, uno de los cantones en el que el suicidio ${ }^{16}$ ha sido un tema preocupante en las últimas décadas (Según Molina, 2019; aproximadamente, 120 en dos décadas), la pregunta por la vida y la muerte, la tragedia y el suicidio estén presentes en las creaciones de las personas adolescentes. Estas obras plantean el conflicto de las intervenciones silenciosas que se realizan en temas tan importantes, demostrando que son temáticas cotidianas que tienen una presencia en el mundo adolescente y, en contraste, son un tabú en el mundo adulto. Debemos repensar las intervenciones en el tema de la muerte (y otras temáticas como el uso de drogas y la sexualidad), para no intentar "educar" y "guiar", sino brindar un acompañamiento a las personas jóvenes en espacios que les permitan organizar su propio discurso frente a estas interrogantes.

\section{Referencias}

Allouch, J. (1995). Erótica del duelo en el tiempo de la muerte seca. Edelp. Antillón, M. (2003, 22 de junio). Alarma aumento en intentos de suicidios. La Nación. https://www.nacion. com/el-pais/alarma-aumento-en-intentos-de suicidio/2DNIX6KQINHRRJYDFI3X62EJBU/story/

Barrantes Araya, T. (2010). San Ramón Tierra de poetas. Revista Estudios, (23), 89-102.

Barbosa, A., Hernández, M., Ugalde, A. y Valverde, X. (2006). Factores sociofamiliares que propician las ideas e intentos de autoeliminación en los y las adolescentes atendidos en el Área de Salud de San Ramón: Bases para una propuesta de intervención desde el trabajo social [tesis de licenciatura, Universidad de Costa Rica].

Blos, P. (1986). Psicoanálisis de la adolescencia. Editorial Joaquín Mortiz.

Bordeu, R. (1995). "Psicoanálisis y literatura: Alejandra Pizarnik y el silencio”. El Anuario del Magíster. Universidad de Chile.

Brenes, L. y Lobo, M. (2009). Autoexpresión desde la arteterapia: Un estudio exploratorio con un grupo de ocho adolescentes de la comunidad de Pueblo Nuevo de Pavas [tesis de licenciatura, Universidad de Costa Rica].

Canal, M. (2013). Dibujo de apuntes. Aula de dibujo. Parramón.

Chinchilla, S. (2016, 11 de setiembre). Cinco cantones encienden las alertas por suicidios. Se atenderá población vulnerable de Dota, Talamanca, Cartago, La Cruz y San Ramón. La Nación. https://www.nacion.com/el-pais/salud/cincocantones-encienden-las-alertas por-suicidios/4 IMLLGTZGBAJ3BTRPZPVJWHWLY/story/

16 Antillón, 2003; Barbosa, Hernández, Ugalde y Valverde, 2006; Chinchilla, 2016. 
Denzin, N. y Lincoln, Y. (2005). The Discipline and Practice of Qualitative Research. SAGE Publications Inc.

Erikson, E. (1968). Identity: Youth and crisis. Norton.

Erikson, E. (1978). Sociedad y adolescencia. Siglo XXI Editores, S.A.

Fernández, M. (1999). La adolescencia en tanto encuentro con la muerte: un estudio conceptual desde el psicoanálisis. Universidad de Costa Rica.

Firpo, S., Lassalle, A., Ortega, A., Díaz, N., Prates, C. y Sansarricq, J. (2000). Clínica psicoanalítica con adolescentes. Homo Sapiens.

Freud, S. (1986a). El creador literario y el fantaseo. Obras Completas. Volumen IX. Amorrortu Editores.

Freud, S. (1986b). El interés por el psicoanálisis. Obras Completas. Volumen XIII. Amorrortu Editores.

Freud, S. (1986c). Duelo y melancolía. Obras Completas, Tomo XIV. Amorrortu Editores.

Freud, S. (1986d). El porvenir de una ilusión. Obras Completas, Tomo XXI. Amorrortu Editores

Freud, S. (1992). El malestar en la cultura. Obras Completas, Tomo XXI. Amorrortu Editores.

García, M (2011). El video como herramienta de investigación. Una propuesta metodológica para la formación de profesionales en comunicación. Enlaces, revista del CES Felipe II, (3), 1-12.

Grossman, D. (2011). Escribir en la oscuridad. Debolsillo.

Gurdián, A. (2007). El paradigma cualitativo en la investigación socio-educativa. Investigación y Desarrollo Educativo Regional (IDER). PrintCente

Herrera, A., Hernández, G. y Alvarado, H. (1996). "Biografemas”. Inscribir el psicoanálisis, vol. 5. ACIEPS: Costa Rica.
Hernández, R., Fernández, C., Baptista, M. (2014). Metodologías de la investigación. Mac Graw Hill Editora.

Hounie, A. (2014). La subjetividad comprometida: fragmento para una estética del dolor. Clínica Psicoanalítica y Lazo Social. UDELAR.

Ioskyn, J. (2013). Literatura y vacío. Psicoanálisis, escritura, escritores. Letra Viva.

Mariscotti, P. (2013). Articulaciones entre el psicoanálisis y la danza. Mayeútica Institución Psicoanalítica.

Maruottolo, C. (2013). La subjetividad como tercera tópica psicoanalítica. Conceptos de su metapsicología y clínica. Norte de salud mental, XI(47), 16-26.

Molina, L. (200o). Escritura y psicoanálisis [tesis de maestría, Universidad Veracruzana].

Molina, S. (2019, 5 de junio). Los suicidios aumentan en Costa Rica ocultos entre las comunidades. Semanario Universidad. https:// semanariouniversidad.com/especiales/suicidiosaumentan-en-costa-rica/

Morales, H. (2011). Otra historia de la sexualidad. Ensayos Psicoanalíticos. Ediciones de la noche.

Murillo, R. (2010). La efectuación del estrago materno en la constitución de la feminidad. De lo psicosomático a la escritura una lectura psicoanalítica de la novela Las palabras para decirlo de Marie Cardinal [tesis de maestría, Universidad de Costa Rica].

Poe, K. (2007a). Eros pervertido, erotismo, cuerpo y autoficción en la novela decadente hispanoamericana (Programa de Doctorado en Estudios de la Sociedad y la Cultura). Universidad de Costa Rica.

Poe, K. (2007b). Escrituras autobiográficas: ¿confesión o autoficción? Universidad de Costa Rica. 
Poe, K. (2013). Almodóvar y Freud. Editorial Laerte.

Quesada I. y Quesada N. (2004). Desarrollo de un programa de danza $\mathrm{y} / \mathrm{o}$ movimiento creativo: una estrategia alternativa para fomentar el bienestar psicológico de adolescentes con discapacidad visual [tesis de licenciatura, Universidad de Costa Rica].

Salas, S. y Arce, L. (2005). Psicoterapia del movimiento: una propuesta de trabajo en la comunicación de emociones de pacientes esquizofrénicos [tesis de licenciatura, Universidad de Costa Rica].

Sebiani L. (2005). Uso de la danza-terapia en la adaptación psicológica a enfermedades crónicas. (Cáncer, fibrosis, sida). Revista Reflexiones, 84(1), 49-56.

Solano, R. (1991). Leer al detalle: literatura, psicoanálisis, teoría literaria [tesis de licenciatura, Universidad de Costa Rica].

Tubert, S. (1982). La muerte y lo imaginario en la adolescencia. Editorial Saltés.

Volosín, S. (2002). Del misterio del silencio a la danza y el verbo. Encuentro Internacional en Barcelona en homenaje a Donald Meltzer. Grupo Psicoanalítico de Barcelona. 